\title{
Hubungan Pengetahuan dan Dukungan Keluarga terhadap Perawatan Diri Penderita Kusta di RSUP Dr. Sitanala Kota Tangerang
}

\author{
Ainun Wulandari, Maisya Rivita \\ Program Studi Farmasi, Fakultas Farmasi, Institut Sains dan Teknologi Nasional
}

\begin{abstract}
Abstrak
Latar belakang: Kusta atau lepra disebabkan oleh Mycobacterium leprae dan dikategorikan sebagai penyakit menular. Kusta termasuk salah satu masalah kesehatan di beberapa negara. Disabilitas permanen dan gangguan kualitas hidup merupakan ancaman kesehatan bagi penderitanya jika tidak ditangani. Selain pengobatan dengan Multi Drug Therapy (MDT), penderita kusta perlu memperhatikan perawatan diri secara kontinyu seumur hidupnya. Perawatan diri ini dapat mencegah disabilitas dan juga memburuknya disabiltas pada penderita kusta. Studi ini ditujukan untuk mengetahui hubungan pengetahuan dan dukungan keluarga terhadap perawatan diri penderita kusta di RSUP Dr. Sitanala Kota Tangerang.

Metode: Penelitian cross sectional ini dilakukan pada Juli 2020 melalui wawancara menggunakan kuesioner. Penelitian ini dilakukan di Poli Kusta RSUP Dr. Sitanala Kota Tangerang dengan responden sebanyak 83 orang dan dianalisis menggunakan uji Fisher's Exact.

Hasil: Berdasarkan hasil penelitian diketahui bahwa pengetahuan tidak memiliki hubungan terhadap perawatan diri penderita kusta di RSUP Dr. Sitanala Kota Tangerang ( -value=0,069) dan terdapat hubungan antara dukungan keluarga terhadap perawatan diri penderita kusta rawat di RSUP Dr. Sitanala Kota Tangerang ( $p$-value $=0,003)$.

Kesimpulan: Hasil penelitian menunjukkan bahwa penderita kusta yang memiliki pengetahuan baik ataupun kurang baik melakukan perawatan diri yang sama. Dukungan keluarga memiliki peranan penting dalam memotivasi penderita kusta untuk melakukan perawatan diri yang baik.
\end{abstract}

Kata kunci: Kusta, Pengetahuan, Dukungan Keluarga, Perawatan Diri.

\section{Relationship between Knowledge and Family Support for Self-Care of Leprosy Patients in RSUP Dr. Sitanala Kota Tangerang}

\begin{abstract}
Background: Leprosy or leprosy is caused by Mycobacterium leprae and is categorized as an infectious disease. Leprosy is one of the health problems in several countries. Permanent disability and disruption quality of life are a health threat to sufferers if not treated. In addition to treatment with Multi Drug Therapy (MDT), selfocare must be carried out by leprosy patients continuously throughout their lives. This self-care can prevent disability and also a worsening of disability in patients with leprosy. This study was conducted to determine the relationship between knowledge and family support for self-care of leprosy patients at RSUP Dr. Sitanala, Tangerang City.

Methods: A cross sectional study was performed during July 2020 by interview using questionnaires. This research was conducted at the Leprosy Poly Dr. Sitanala Central Hospital Tangerang City with 83 respondents and were analyzed using the Fisher's Exact test.

Result: The result showed that knowledge had no relationship with self-care of leprosy patients at Dr. Sitanala Hospital, Tangerang City ( $p$-value $=0.069)$, while there was a relationship between family support for self-care of leprosy patients at Dr. Sitanala Hospital, Tangerang City ( $p$-value $=0.006)$.

Conclusion: The results showed that leprosy patients who had good or poor knowledge did the same self-care. Family support has an important role in motivating good self-care of leprosy patients.
\end{abstract}

Key Words: Leprosy, Knowledge, Family Support, Self-Care.

Korespondensi: Ainun Wulandari Email: ainun_wulandari@istn.ac.id 


\section{PENDAHULUAN}

Kusta termasuk salah satu penyakit menular disebabkan oleh Mycobacterium leprae. Kusta menyerang saraf tepi/perifer, kemudian kulit, dan dapat mengenai organ tubuh lain seperti mata, mukosa saluran napas atas, otot, tulang dan terkadang testis. Kusta banyak ditemukan di beberapa negara berkembang karena keterbatasan pelayanan kesehatan maupun pendidikan. Ditambah dengan rendahnya kesejahteraan sosial dan ekonomi. ${ }^{1}$ Permasalahan yang ditimbulkan oleh kusta tidak hanya dalam aspek kesehatan, tetapi juga sosial-ekonomi dan budaya. ${ }^{2}$

Data World Health Organization (WHO) pada tahun 2019 melaporkan adanya 202.256 kasus baru dari 118 negara dengan Indonesia pada peringkat ke-3 setelah India dan Brazil. ${ }^{3}$ Prevalensi kusta di Indonesia pada tahun 2019 sebesar 0,74 kasus/10.000 penduduk dan jumlah kasus baru di Indonesia 17.439 kasus dengan angka penemuan kasus baru 6,51 per 100.000 penduduk. Untuk mengendalikan angka kejadian kasus kusta perlu dilakukan pendeteksian kasus sejak dini. ${ }^{4}$

Pengobatan kusta perlu dilakukan semenjak dini dan ditangani dengan cepat dan tepat. Semakin lama dimulainya pengobatan kusta sejak saat pertama ditemukan tanda, akan meningkatkan risiko disabilitas yang diakibatkan kerusakan saraf secara progresif pada saraf tepi. ${ }^{2}$ Keterlambatan dalam deteksi dini juga terbukti meningkatkan jumlah kasus baru dengan derajat disabilitas tingkat 2 yang relatif tinggi. ${ }^{5}$

Stigma di masyarakat menyebabkan penderita tertutup secara sosial yang menghambat petugas kesehatan menemukan kasus dan keterlambatan tatalaksana. Pengetahuan masyarakat mengenai gejala awal kusta, penatalaksanaan kusta secara komprehensif belum optimal, dan keterbatasan fasilitas penunjang dalam mendeteksi penyakit kusta karena secara klinis penyakit kusta mirip dengan penyakit kulit lainnya juga menjadi hambatan. ${ }^{1}$ Stigma sosial dalam keluarga dan masyarakat membuat kepercayaan diri penderita kusta berkurang dan merasa takut akan kecatatan yang diakibatkan dikemudian hari sehingga melakukan pengasingan secara spontan. ${ }^{6}$

Faktor resiko lainnya yang dapat meningkatkan angka kejadian kusta adalah status ekonomi, vaksinasi BCG, pendidikan, pekerjaan, pengetahuan, riwayat kontak penderita, personal hygiene (kebiasaan mandi, meminjam handuk, penggunaan alas kaki), kondisi fisik rumah (kepadatan hunian, kondisi lantai rumah, ventilasi, pencahayaan, kelembaban), dan sumber air bersih. ${ }^{7-9}$

Untuk mencegah disabilitas juga diperlukan pengobatan yang akurat, WHO merekomendasikan pengobatan kusta dengan Multi Drug Therapy (MDT) yang dikombinasikan dari dua atau lebih obat anti kusta semisal rifampisin sebagai bakterisidal anti kusta kuat sedangkan lainnya bersifat bakteriostatik $^{1}$ Serta memberikan rifampisin dosis tunggal untuk orang atau keluarga yang kontak dengan penderita kusta. Pengobatan tersebut terbukti menurunkan angka kejadian kusta dan memutus mata ranti penularan kusta. $^{3}$

Pengobatan MDT yang dilakukan oleh penderita kusta sudah atau akan membunuh bakteri kusta, tetapi selama pengobatan sebagian besar penderita kusta mengalami reaksi kusta dan kerusakan saraf yang mengakibatkan disabilitas. Untuk mencegah terjadinya disabilitas dan memburuknya disabilitas, penderita dan orang yang pernah mengalami kusta (OYPMK) perlu melakukan perawatan diri/ self-care secara kontinue seumur hidup mereka. Perawatan diri yang dilakukan meliputi $3 \mathrm{M}$ yaitu Memeriksa, Merawat, dan Melindungi. Penderita dan keluarga dapat melakukan perawatan diri secara mandiri di rumah setiap hari. ${ }^{2,3}$ Perawatan diri ini diharapkan dapat menurunkan stigma, diskriminasi, dan kualitas hidup penderita beserta keluarga.

Stigma terhadap penderita kusta ini terjadi karena kurangnya pengetahuan masyarakat terhadap penyakit kusta dan bahwa disabilitas ini dapat disembuhkan. Dukungan keluarga memainkan peran penting dalam setiap aspek perawatan penderita, terutama dalam pengobatan dan perawatan diri. Dukungan keluarga berupa perhatian perhatian, perasaan, dan sikap selama masa pengobatan. ${ }^{10}$ Peran keluarga sebagai unit terkeceil dan terdekat dengan penderita kusta dalam memberikan perawatan dan dukungan sangat diperlukan. ${ }^{11}$

Pengetahuan penderita kusta dan dukungan keluarga merupakan faktor yang menunjang keberhasilan dalam melakukan perawatan diri guna mencegah dan 
memperburuk disabilitas pada penderita kusta. Studi ini dilakukan untuk menilai keterkaitan antara pengetahuan dan dukungan keluarga terhadap perawatan diri panderita kusta di RSUP Dr. Sitanala Kota Tengerarang. RSUP Dr. Sitanala awalnya adalah rumah sakit khusus untuk penderita kusta yang memiliki keinginan untuk menghilangkan stigma negatif terkait penyakit kusta.

\section{METODE}

Studi cross sectional ini dilakukan di poli kusta RSUP Dr. Sitanala Kota Tangerang pada bulan Juli 2020 selama pandemic Covid19 dengan populasi seluruh penderita kusta yang terdaftar dan masih melakukan pengobatan di pada bulan Juni 2020 yaitu sebanyak 105 responden. Pandemi menyebabkan penurunan kunjungan penderita kusta ke RSUP Dr. Sitanala Kota Tengerang dan keterbatasan jumlah sampel penelitian ini. Perhitungan sampel minimal dihitung menggunakan rumus Slovin dengan margin of error 5\%, didapatkan sampel sebesar 83 orang yang dipilih secara simple random sampling. ${ }^{12}$

Kuesioner digunakan untuk pengambilan data primer yang terdiri dari empat bagian yaitu karakteristik responden, pengetahuan penderita, dukungan keluarga, dan perawatan diri penderita. Variabel pengetahuan di jawab dengan menggunakan skala guttman, sedangkan varaibel dukungan keluarga dan perawatan diri penderita menggunakan 4 skala likert (selalu, sering, kadang-kadang, dan tidak pernah).

Hasil ukur variabel pengetahuan, dukungan keluarga dan perawatan diri dikategorikan menjadi tiga tingkat yang didasarkan dari nilai persentase yaitu sebagai berikut. ${ }^{13}$

a. Baik, jika nilainya $\geq 76 \%-100 \%$

b. Cukup, jika nilainya $\geq 56 \%-75 \%$

c. Kurang, jika nilainya $<56 \%$

Variabel bebas yaitu pengetahuan penderita dan dukungan keluarga, sedangkan variabel terikatnya adalah perawatan diri penderita kusta. Uji statistic yang digunakan yaitu Fisher's exact.

Hipotesis yang ditetapkan dalam penelitian ini ada 2, yaitu:

1. Tingkat pengetahuan penderita memiliki hubungan terhadap perawatan diri penderita kusta di RSUP Dr. Sitanala Kota Tangerang.
2. Dukungnan keluarga memiliki hubungan terhadap perawatan diri penderita kusta di RSUP Dr. Sitanala Kota Tangerang.

Kuesioner yang dugunakan dalam penelitian ini telah dilakukan uji validitas dan relialibilitas sebelumnya kepada 30 responden. Uji validitas dilakukan untuk mengukur apakah pertanyaan dalam kuesioner mampu mengukur konsep yang diukur. Kuesioner yang digunakan memperoleh $\mathrm{r}$ hitung lebih dari 0,361 sehingga semua pertanyaan dikatakan valid. Setelah semua pertanyaan valid kemudian dilakukan uji validitas, untuk mengukur sejauh mana kuesioner dapat dipercaya atau diandalkan. Kusioner ini reliabel karena nilai Cronbach alpha menunjukkan $\geq 0,6 .{ }^{14}$

\section{HASIL}

Table 1. Distribusi Berdasarkan Jenis Kelamin, Usia, dan Vaksin BCG Penderita Kusta di RSUP Dr. Sitanala Kota Tangerang

\begin{tabular}{ccc}
\hline Karakteristik & $\begin{array}{c}\text { Jumlah } \\
\text { (n) }\end{array}$ & $\begin{array}{c}\text { Persentase } \\
(\%)\end{array}$ \\
\hline Jenis Kelamin & & \\
Laki-laki & 56 & 67,5 \\
Perempuan & 27 & 32,5 \\
& 83 & 100 \\
Usia & & \\
17-25 Tahun & 14 & 16,9 \\
26-35 Tahun & 14 & 16,9 \\
36-45 Tahun & 23 & 27,7 \\
46-55 Tahun & 15 & 18 \\
56-65 Tahun & 17 & 20,5 \\
& 83 & 100 \\
Vaksin BCG & & \\
Belum & 75 & 90,4 \\
Sudah & 8 & 9,6 \\
& 83 & 100 \\
\hline
\end{tabular}

Hasil analisis karakteristik responden pada Tabel 1 menunjukan bahwa mayoritas penderita kusta berjenis kelamin laki-laki (67,5\%). Usia responden yang berumur rentang dari 17-25 tahun berjumlah 14 responden $(16,9)$ dimana rentang umur tersebut dikategorikan sebagai masa remaja, sedangkan responden yang berumur rentang dari 26-35 tahun berjumlah 14 responden $(16,9)$ di mana rentang umur tersebut dikategorikan sebagai masa dewasa. Lalu responden yang berumur rentang dari 36-45 tahun berjumlah 23 responden $(27,7 \%)$ dengan kategori masa dewasa akhir. Kemudian responden yang 
berumur rentang dari 46-55 tahun berjumlah 15 responden $(18,1 \%)$ dengan kategori masa lansia awal dan responden yang berumur rentang dari 55-65 tahun berjumlah 17 responden $(20,5 \%)$ kategori masa lansia akhir. Sebagian besar responden belum melakukan vaksin BCG sebanyak 75 orang $(90,4 \%)$ dan responden yang sudah melakukan vaksin $\mathrm{BCG}$ hanya 8 orang $(9,6 \%)$ dari total jumlah responden sebanyak 83 orang.

Tabel 2 Distribusi Berdasarkan Variabel Pengetahuan, Dukungan

Keluarga, dan Perawatan Diri Penderita Kusta di RSUP Dr. Sitanala Kota Tangerang

\begin{tabular}{lcc}
\hline Karakteristik & $\begin{array}{c}\text { Jumlah } \\
\text { (n) }\end{array}$ & $\begin{array}{c}\text { Persentase } \\
(\%)\end{array}$ \\
\hline Pengetahuan & & \\
Kurang & 23 & 27,7 \\
Cukup & 49 & 59 \\
Baik & 11 & 13,3 \\
& 83 & 100 \\
Dukungan Keluarga & & \\
Kurang & 49 & 59 \\
Cukup & 25 & 30,1 \\
Baik & 9 & 10,9 \\
& 83 & 100 \\
Perawatan Diri & & \\
Kurang & 63 & 75,9 \\
Cukup & 18 & 21,7 \\
Baik & 2 & 2,4 \\
& 83 & 100 \\
\hline
\end{tabular}

Berdasarkan Tabel 2 pengetahuan responden terkait penyakit kusta yang bernilai kurang sebesar 23 responden $(27,7 \%)$, untuk nilai cukup sebanyak 49 responden $(59,0 \%)$ dan untuk nilai baik 11 responden $(13,3 \%)$. Tingkat pengetahuan responden paling paling banyak dikategori cukup. Lebih dari setengah responden mendapatkan dukungan keluarga dengan kategori kurang (59\%). Perawatan diri penderita kusta menunjukkan sebagian besar dalam kategori kurang 75,9\%. Hasil penelitian ini menunjukan bahwa perawatan diri pada penderita kusta masih sangat rendah, karena terdapat $75,9 \%$ responden berada dalam kategori kurang untuk variabel perawatan diri.

Hasil analisis tabulasi silang pada Tabel 3 diketahui bahwa sebagian besar responden memiliki pengatahuan cukup sebanyak 49 reponden (59\%). Sebanyak 33 responden memiliki perilaku kurang dalam melakukan perawatan diri, 14 orang cukup, dan 2 orang baik. Hal ini menunjukkan bahwa meskipun sebagian besar responden memiliki pengetahuan cukup, tetapi memiliki perawatan diri yang kurang terhadap penyakit kusta.

Tabel yang dianalisis adalah tabel $3 \times 3$. Tabel tersebut memiliki lima sel yang nilai ekspektasinya kurang dari lima. Dengan demikian, data tersebut tidak dapat dianalisis dengan uji Chi-square melainkan dengan uji Fisher's exact. Hasil uji hubungan tingkat pengetahuan terhadap perawatan diri didapatkan $p$-value sebesar 0,069 sehingga tidak terdapat hubungan yang signifikan antara pengetahuan terhadap perilaku perawatan diri pada penderita kusta.

Tabel 3 Hubungan Pengetahuan terhadap Perawatan Diri Penderita Kusta di RSUP Dr. Sitanala Kota Tangerang

\begin{tabular}{cccccccc}
\hline \multirow{2}{*}{ Pengetahuan } & \multicolumn{3}{c}{ Perawatan Diri } & \multirow{2}{*}{ Total } & \multirow{2}{*}{ p-value } \\
\cline { 3 - 5 } Kurang & $\mathrm{N}$ & Kurang & Cukup & Baik & & \\
& $\%$ & $26,5 \%$ & $1,2 \%$ & $0,0 \%$ & $27,7 \%$ & \\
\multirow{2}{*}{ Cukup } & $\mathrm{N}$ & 33 & 14 & 2 & 49 & \\
& $\%$ & $39,8 \%$ & $16,9 \%$ & $2,4 \%$ & $59,0 \%$ & \multirow{2}{*}{ Baik } \\
& $\mathrm{N}$ & 8 & 3 & 0 & 11 & 0,069 \\
& $\%$ & $9,6 \%$ & $3,6 \%$ & $0,0 \%$ & $13,3 \%$ & \\
\multirow{5}{*}{ Total } & $\mathbf{N}$ & 63 & 18 & 2 & 83 & \\
& $\mathbf{\%}$ & $75,9 \%$ & $21,7 \%$ & $2,4 \%$ & $100,0 \%$ & \\
\hline
\end{tabular}


Tabel 4 Hubungan Dukungan Keluarga

terhadap Perawatan Diri Penderita Kusta di RSUP Dr. Sitanala Kota Tangerang

\begin{tabular}{lccccc}
\multirow{2}{*}{$\begin{array}{c}\text { Dukungan } \\
\text { Keluarga }\end{array}$} & \multicolumn{3}{c}{ Perawatan Diri } & Total \\
\cline { 3 - 6 } & & Kurang & Cukup & Baik \\
\hline \multirow{2}{*}{ Kurang } & $\mathrm{N}$ & 43 & 4 & 2 & 49 \\
& $\%$ & $51,8 \%$ & $4,8 \%$ & $2,4 \%$ & $59,0 \%$ \\
\multirow{4}{*}{ Cukup } & $\mathrm{N}$ & 15 & 10 & 0 & 25 \\
\multirow{4}{*}{ Baik } & $\%$ & $18,1 \%$ & $12,0 \%$ & $0,0 \%$ & $30,1 \%$ \\
& $\mathrm{~N}$ & 5 & 4 & 0 & 9 \\
\multirow{2}{*}{ Total } & $\%$ & $6,0 \%$ & $4,8 \%$ & $0,0 \%$ & $10,8 \%$ \\
& $\mathrm{~N}$ & 63 & 18 & 2 & 83 \\
& $\%$ & $75,9 \%$ & $21,7 \%$ & $2,4 \%$ & $100,0 \%$ \\
\hline
\end{tabular}

Pada Tabel 4 menunjukan bahwa sebagian besar penderita kusta kurang mendapatkan dukungan dari keluarganya. Jumlah responden dengan dukungan keluarga yang kurang memiliki perilaku kurang juga dalam melakukan perawatan diri sebanyak 43 responden, 4 responden dengan perilaku perawatan diri cukup, dan sisanya 2 responden memiliki perilaku perawatan diri baik. Analisis hubungan dukungan keluarga terhadap perawatan diri dengan menggunakan uji Fisher's exact didapatkan nilai $p$-value sebesar 0,003 sehingga dapat dikatakan terdapat hubungan yang signifikan antara dukungan keluarga terhadap perilaku perawatan diri pada penerita kusta.

\section{PEMBAHASAN}

\section{Gambaran Karakteristik Responden}

Kusta dapat menyerang semua kategori jenis kelamin dan usia. Banyak faktor yang menyebabkan seseorang menderita kusta. Namun, penelitian di RSUP Dr. Sitanala Kota Tangerang tahun 2020 menunjukkan mayoritas penderita berjenis kelamin laki-laki. Begitu pula dengan penelitian di RS. Dr. Tadjuddin Chalid Makassar tahun 2015 dan di Kabupaten Lamongan tahun 2017 dimana lakilaki lebih banyak menderita kusta dari pada perempuan. ${ }^{7,6}$ Perbandingan penderita kusta laki-laki dan perempuan yaitu 2:1 dengan kejadian kusta saraf murni atau pure neural leprosy sebagian besar penderitanya adalah laki-laki. Faktor sosial budaya kemungkinan sebagai faktor penting dalam rendahnya kasus kusta pada perempuan. ${ }^{1}$ Rendahnya status sosial perempuan di beberapa daerah di Indonesia mengakibatkan keterbatasan perempuan dalam mengakses pelayanan kesehatan sehingga memungkinkan kasus tersembunyi pada kalangan perempuan. Selain itu laki-laki lebih banyak melakukan aktivitas di luar rumah sehingga resiko untuk untuk terpapar juga lebih besar. ${ }^{15}$

Usia responden yang terbanyak berada pada rentang 36-45 tahun atau dikategorikan sebagai masa dewasa dimana pada usia tersebut penderita kusta masih berada dimasa produktif. Manusia lebih rentan mengalami berbagai penyakit saat usia produktif karena mobilitas dan aktivitas lebih tinggi dibandingkan dengan usia balita atau lansia. Pada usia produktif juga mulai mengalami penuaan sehingga jaringan mulai kehilangan kemapuan regenerasi sehingga rentan terhadap infeksi penyakit. ${ }^{16,17}$ Temuan penelitian ini sesuai dengan penelitian di Puskesmas Grati tahun 2017 dan Puskesmas Ponggok serta Puskesmas Sutojayan tahun 2017, di mana penderita kusta paling banyak berada pada rentang usia produktif. ${ }^{11,18}$

Sebanyak 75 responden dari 83 responden belum melakukan vaksin BCG. Hal ini menunjukan bahwa kesadaran diri masyarakat untuk melakukan vaksin masih rendah. Pemberian vaksin BCG saat lahir terbukti efektif mampu untuk mengurangi resiko kejadian kusta dan pemberian vaksin ini sangat dianjurkan terutama untuk negara dengan prevalensi kusta yang tinggi. Pemberian vaksin BCG dapat menurunkan kejadian kusta dan memberikan perlindungan terhadap gejala kusta hingga $80 \% .^{3}$ Hal ini didukung oleh penelitian dari Aprizal tahun 2017 menunjukkan vaksinasi BCG merupakan salah satu faktor yang berhubungan secara statistik dengan kejadian kusta. ${ }^{7}$

\section{Pengetahuan Penderita Kusta}

Penelitian di RSUP Dr. Sitanala Kota Tangerang menunjukkan hasil $59 \%$ penderita memiliki pengetahuan cukup. Temuan ini sesuai dengan penelitian yang dilakukan oleh Astutik \& Kiptiyah $^{19}$ dan Hidayah, dkk. ${ }^{20}$ Pengetahuan penderita kusta ini perlu ditingkatkan karena dengan pengetahuan yang baik, penderita kusta akan memiliki kesadaran dan kemampuan untuk memelihara kesehatan mereka sendiri dengan benar dan tepat. Pemahaman dan kesadaran yang kurang mengenai perawatan diri penderita kusta akan berbanding lurus dengan rendahnya pemenuhan kemampuan aktivitas sehari-hari serta kualitas hidup penderita. ${ }^{21}$ Selain itu, 
pengetahuan akan memperkuat terbentuknya perilaku. ${ }^{22}$

Pengetahuan ini tidak hanya diperlukan oleh penderita melainkan juga oleh keluarga dan masyarakat, dengan pengetahuan masyarakat yang baik mengenai penyakit kusta harapannya mampu menurunkan stigma dan dsikriminasi pada penderita kusta, deteksi dini cepat penyakit kusta, pengobatan lebih cepat dan tuntas, mencegah disabilitas, dan memutus mata rantai penuluaran kusta.

\section{Dukungan Keluarga Penderita Kusta}

Dukungan keluarga dangat dibutuhkan dalam proses penyembuhan penderita kusta baik secara fisik maupun psikologis bagi penderita. Penderita kusta seringkali mengalami depresi karena adanya stigma, sehingga mengakibatkan penurunan kualitas hidup dan pengobatan menjadi tidak tuntas. ${ }^{1}$

Penelitian ini menemukan hasil yang serupa dengan Nur Laili yaitu kurangnya dukungan keluarga kepada responden. Pemahaman yang kurang dari keluarga mengenai kusta menyebabkan kurangnya dukungan keluarga. Dalam hal ini, keluarga tidak memahami kondisi dari penderita kusta sehingga tidak ada upaya literasi mengenai penanganan kusta. Selain itu ditambah kemungkinan kurangnya literasi yang menyebabkan penderita dan keluarga tidak memahami tingkat kecacatan akibat kusta. Pada tahap awal, penderita kusta terlihat seperti orang normal sehingga banyak kasus yang terlambat ditangani. ${ }^{11}$

\section{Perawatan Diri Penderita Kusta}

Perawatan diri perlu dilakukan untuk mencegah timbulnya disabilitas dan memburuknya keaadaan disabilitas sehingga produktivitas tetap terjaga. Penelitian ini menunjukan $75,9 \%$ responden memiliki perilaku yang kurang dalam melakukan perawatan diri. Hasil tersebut didukung olehpenelitian Nur Laili yaitu responden hanya melakukan perawatan diri kurang dari 56\% dari keseluruhan rangkaian perawatan diri yang harus dilakukan. ${ }^{11}$

Perawatan dari kusta perlu dilakukan sejak awal sescara kontinue seumur hidup. Pada tahap awal kusta, penderita tidak langsung mengalami kerusakan saraf, mati rasa pada beberapa bagian tubuh ataupun luka. Hal ini menyebabkan beberapa responden tidak melakukan perawatan diri, sedangkan pada tahap awal itulah dimana penderita dapat melakukan pencegahan dengan perawatan diri agar tidak terjadi kecacatan yang berlanjut.

\section{Hubungan Pengetahuan terhadap Perawatan Diri Penderita Kusta}

Hasil penelitian ini menunjukan bahwasanya pengetahuan terkait penyakit kusta tidak memiliki hubungan terhadap perawatan diri responden. Temuan ini sesuai dengan penelitian perilaku perawatan diri di Unit Pelayanan Terpadu Rehabilitasi EksPenderita Kusta Nganget, Tuban. Penelitian tersebut menemukan tidak ada perbedaan pengetahuan dalam hal perilaku perawatan diri. Kondisi ini kemungkinan disebabkan responden mendapatkan tingkat pengetahuan yang sama sebelum dan sesudah rehabilitasi. ${ }^{19}$

Berbeda dengan temuan dari Hidayah, dkk. yaitu tingkat pengetahuan memiliki hubungan dengan praktik perawatan diri pada penderita kusta di Kota Semarang. ${ }^{20}$ Berlawanan juga dengan teori dari Lawrence Green mengenai faktor predisposisi, faktor pemungkin, dan faktor penguat. Menurut teorit tersebut, kemungkinan terdapat faktor diluar ketiga faktor tersebut yang mempengaruhi perilaku yang tidak diukur dalam penelitian ini. ${ }^{23}$

Penelitian yang dilakukan oleh Pangestuti, dkk. menunjukkan bahwa di lapangan mayoritas penderita kusta tidak melakukan perawatan diri secara mandiri di rumah sehingga bergantung pada perawatan di fasilitas kesehatan. Penderita hanya melakukan perawatan diri ketika datang ke rumah sakit saja. Meskipun penderita kusta memiliki pengetahuan mengenai bagaimana perawatan diri, penderita tidak mau atau malas mengaplikasikannya di rumah. Perawatan diri penderita kusta seharusnya dilakukan setiap hari dengan mandiri ketika di rumah untuk mencegah kejadian dan peningkatan derajat disabilitas. ${ }^{24}$

\section{Hubungan Dukungan Keluarga terhadap Perawatan Diri Penderita Kusta}

Hasil penelitian ini menjelaskan bahwa dukungan keluarga memegang peranan penting dalam perawatan diri penderita kusta. Dikarenakan keluarga merupakan orang terdekat dengan penerita kusta, dan juga 
penderita kusta membutuhkan dukungan yang bertujuan agar penderita merasa diperhatikan sehingga akan mempengaruhi kesehatan serta perawatan dirinya. Temuan studi ini sesuai dengan temuan Zakiyah bahwa dukungan keluarga yang adekuat akan memperkuat kedisiplinan dalam perawatan diri terutama mengenai frekuensi hingga tata cara yang tepat. Keluarga menempati peran penting karena keluarga merupakan tempat penderita meminta saran maupun berbagi pendapat. Selain itu, keluarga juga dapat berperan aktif dalam mengingatkan waktu minum obat untuk meningkatkan penyembuhan. ${ }^{25}$

Menurut hasil penelitian Astutik \& Kiptiyah juga dalam penelitian ini, penderita kusta dengan dukungan keluarga baik cenderung melakukan tindakan perawatan diri dengan tepat dan sesuai kondisinya. ${ }^{19}$ Terlihat bahwa dukungan keluarga memainkan peran penting dalam motivasi penderita kusta untuk melakukan perawatan diri kusta. Tidak meninggalkan penderita kusta juga merupakan dukungan keluarga yang sangat penting dan dibutuhkan. $^{20}$ Penderita kusta yang mendapatkan dukungan keluarga yang baik akan meningkatkan kemungkinan waktu penyembuhan dan mengupayakan kesembuhan.

\section{KESIMPULAN}

Pengetahuan dan dukungan keluarga memiliki hubungan terhadap perawatan diri penderita kusta di RSUP Dr. Sitanala Kota Tengarang. Hal ini menunjukkan penderita kusta yang memiliki pengetahua baik ataupun kurang baik tidak memiliki perbedaan dalam perilaku perawatan diri. Dukungan keluarga memiliki peranan penting dalam memotivasi penderita kusta untuk melakukan perawatan diri yang baik. Oleh karena itu disarankan kepada keluarga dan tenaga kesehatan untuk terus memotivasi penderita baik secara emosional, materil maupun spiritual untuk melakukan perawatan diri dengan baik agar terhindar dari disabilitas.

\section{DAFTAR PUSTAKA}

1. Kemenkes RI. Keputusan Menteri Kesehatan Republik Indonesia Nomor HK.01.07/Menkes/308/2019 tentang Pedoman Nasional Pelayanan Kedokteran Tata Laksana Kusta. Jakarta: Kementrian Kesehatan Republik Indonesia; 2019

2. Kemenkes RI. Peraturan Menteri Kesehatan Republik Indonesia Nomor 11
Tahun 2019 tentang Penanggulangan Kusta. Jakarta: Kementrian Kesehatan Republik Indonesia; 2019.

3. WHO. Towards zero leprosy. Global Leprosy (Hansen s disease) Strategy 2021 2030. Geneva: World Health Organization; 2021.

4. Kemenkes RI. Profil Kesehatan Indonesia Tahun 2019. Jakarta: Kementrian Kesehatan Republik Indonesia; 2020.

5. WHO. Report of the first meeting of the WHO Diagnostic Technical Advisory Group for Neglected Tropical Diseases. Geneva: World Health Organization; 2019.

6. Bujiwati E, Nildawati, Syamsu AA. Gambaran Persepsi Pasien Tentang Penyakit Kusta dan Dukungan Keluarga pada Pasien Kusta di RS. Dr. Tadjuddin Chalid Makassar tahun 2015. Al-Sihah: Public Health Science Journal. 2016;8(1):29-38.

7. Aprizal, Lazuardi L, Soebono H. Faktor Resiko Kejadian Kusta di Kabupaten Lamongan. BKM Journal of Community Medicine Public Health. 2017;33(9):427432.

8. Muntasir, Salju EV, Rulianti LP. Studi Faktor-Faktor Yang Berhubungan Dengan Kejadian Penyakit Kusta Pada Wilayah Kerja Puskesmas Bakunase Kota Kupang Tahun 2017. Jurnal Info Kesehatan. 2018;16(2).

9. Fitriya I, Rahayu U, Sunarko B. Hubungan Kondisi Fisik Rumah, Personal Hygiene dengan Kejadian Kusta Tahun 2020 (Di Wilayah Kerja Puskesmas Talango, Kecamatan Talango, Kabupaten Sumenep). Gema Lingkungan Kesehatan. 2021;19(1).

10. Rewa NE, Lea AI, Febriyanti E. Faktorfaktor yang Mempengaruhi Dukungan Keluarga terhadap Motivasi Berobat Penderita Kusta di Wilayah Kerja Puskesmas Se-Kota Kupang. CHMK Applied Scientific Journal. 2021;4(1).

11. Nur Laili AF. Hubungan Dukungan Keluarga dan Pengetahuan Terhadap Perawatan Diri Penderita Kusta di Puskesmas Grati Tahun 2016. The Indonesian Journal of Public Health. 2017;12(1):13-26. 
12. Sugiyono. Metode Penelitian Kuantitatif, Kualitatif, dan R\&D. Bandung: Alfabeta; 2017.

13. Budiman, Riyanto. Kapita Selekta Kuesioner: Pengetahuan dan Sikap dalam Penelitian Kesehatan. Jakarta: Salemba Medika; 2013.

14. Riwidikdo H. Statistik Kesehatan dan Aplikasi SPSS dalam Prosedur Penelitian. Yogyakarta: Rohima Press; 2013.

15. Saragih RA. Gambaran Epidemiologi Penyakit Kusta di Kecamatan Sui Kakap Kabupaten Kubu Raya Provinsi Kalimantan Barat Tahun 2012. Jurnal Mahasiswa PSPD FK Universitas Tanjungpura. 2014;1(2).

16. Kemenkes RI. Profil Kesehatan Indonesia Tahun 2009. Jakarta: Kementrian Kesehatan Republik Indonesia; 2010.

17. Makalew DA, Kapantow GM, Pandaleke HEJ. Profil Penderita Morbus Hansen di Rawat Inap RSUP Prof. Dr. R. D. Kandou Manado Periode 2016-2018. E-Clinic. 2020;8(1):84-90.

18. Mulyadi A, Sepdianto TC, Mitayasari E. Upaya Penderita Kusta dalam Mencegah Peningkatan Derajat Kecacatan. Jurnal Ners dan Kebidanan. 2017;4(3):186-191.

19. Astutik E, Kiptiyah NM. Faktor-faktor yang Berhubungan dengan Perilaku Perawatan Diri Eks-Penderita Kusta di Unit Pelaksana Teknis Rehabilitasi Sosial EksPenderita Kusta Nganget, Tuban, Jawa Timur. Jurnal Epidemiologi Kesehatan Indonesia. November: 2016;1(1):15-21.
20. Hidayah EN, Ginandjar P, Martini, Udiyono A. Hubungan Tingkat Pengetahuan, Sikap dan Tingkat Dukungan Keluarga dengan Praktik Perawatan Diri Pada Penderita Kusta di Kota Semarang. Jurnal Ilmiah Mahasiswa. Januari: 2020;10(1):10-14.

21. Afrida M, Hurah T, Fahmi FY. Gambaran Tingkat Pengetahuan tentang Perawatan Diri (Self-Care) Pada Pasien Hemodialisa RS. PKU Muhammadiyah Yogyakarta. Jurnal Ilmiah Ilmu Kesehatan. 2018;6(1).

22. Notoatmodjo S. Kesehatan Masyarakat Ilmu dan Seni. Jakarta: Rineka Cipta; 2013.

23. Notoatmodjo S. Ilmu Perilaku Kesehatan. Jakarta: Rineka Cipta; 2014.

24. Pangestuti ED, Sriyono, Efendi F. Pengaruh Pendidikan Kesehatan dengan Metode Demonstrasi Terhadap Kemandirian Perawatan Diri pada Pasien Kusta Cacat Tingkat II di Rumah Sakit Sumberglagah Mojokerto. Fundamental \& Management Nursing Journal. 2012;1(1).

25. Zakiyah, I. Pemodelan Kasus Kusta Pausi Basiler dan Kasus Kusta Multi Basiler di Provinsi Jawa Timur Menggunakan Regresi Binominal Negatif Bivariat. Universitas Airlangga; 2017. 